\title{
The Evolution of Political Networks: Evidence from the Council of the European Union*
}

\author{
Narisong Huhe Haniel Naurin $^{\ddagger} \quad$ Robert Thomson ${ }^{\S}$
}

\begin{abstract}
This study tests two of the main explanations of the formation of political ties. The first explanation is based on the homophily principle and states that political actors are more likely to form a relationship if they have similar policy preferences. The second explanation, from network theory, predicts that the likelihood of a tie between two actors depends on the presence of certain relationships with other actors. For instance, two actors are more likely to form a tie if they share many transitive linkages with other actors. We examine the evolution of cooperation networks in the Council of the European Union as a testing ground for propositions from these approaches. Our data consist of a unique combination of actors' policy positions and their network relations over time. We find evidence that both preference similarity and indirect ties affect the development of network relations throughout the Council's committees, although there appears to be significant variation in the extent to which preference similarity affects network evolution. We consider the implications of these findings for the stock of social capital held in the Council and for understanding the consensual mode decision-making highlighted by previous studies of the Council. These issues are highly pertinent given the challenges posed by the prospect of Brexit.
\end{abstract}

*The replication dataset and codes will be available online.

${ }^{\dagger}$ University of Strathclyde. Email: narisong.huhe@strath . ac.uk.

${ }_{\ddagger}^{\ddagger}$ University of Oslo. Email: daniel.naurin@jus.uio.no.

${ }^{\S}$ Monash University. Email: robert . thoms on@monash . edu. 
Why are some political actors more likely to form cooperative relations than others? This question is central to understanding the workings of political systems in which actors both vie for influence over policy outcomes and attempt to solve collective action problems (Heclo, 1978; Laumann and Knoke, 1987; Knoke et al., 1996; Bardach, 1998; Feiock and Scholz, 2009). Two broad types of explanations of political actors' network relations have been advanced (König and Bräuninger, 1998; Carpenter, Esterling and Lazer, 2004; Thurner and Binder, 2009; Berardo and Scholz, 2010; Henry, Lubell and McCoy, 2011; Leifeld and Schneider, 2012). First, homophily refers to the tendency of actors to seek ties with others who hold similar individual social, cultural or political characteristics (McPherson, Smith-Lovin and Cook, 2001). In policy networks, similar policy preferences are likely to induce cooperation as they signal the existence of congruent cognitive frameworks regarding relevant policy problems (Carpenter, Esterling and Lazer, 2004; Gerber, Henry and Lubell, 2013). Moreover, forming coalitions with like-minded actors may increase one's bargaining leverage (Sabatier and Weible, 2007; Leifeld and Schneider, 2012).

Second, network theory holds that characteristics of the larger network within which actors are embedded trigger mechanisms that affect the likelihood that those actors form ties with each other (Coleman, 1988; Putnam, 1993; Schneider et al., 1997; Burt, 2005). For instance, some network models posit that the presence of many transitive and facilitating links between two actors, based on shared relations with third parties, strengthen the social trust they have in each other. This in turn increases the likelihood that a cooperative relation will develop between them. Other characteristics of the network, such as the presence of facilitating and reciprocal links, also feature in network-based explanations of political ties (Henry, Lubell and McCoy, 2011).

The size and direction of the effect of policy preferences compared to network characteristics have strong implications for the impact of cooperation ties on decision-making processes and outcomes. If, for instance, actors tend to cooperate with others who hold similar preferences, then the effects of network ties may strengthen existing preferences. The network will then have little effect on changing policy preferences, but may instead increase polarization within the network. Strong ties between likeminded actors mean that networks reinforce 
differences among clusters and mobilize bias within the system. A downside of homophily, therefore, is group polarization and extremism, and a generally weakened potential for networks to solve collective action problems (Freeman, 1978; Jackson, 2010). By contrast, if actors frequently have ties with others with whom they disagree, network relations may be channels through which disagreements are played out and eventually resolved. If the network structure creates cross-cutting ties, homophilous clusters and polarization may be mitigated.

The potential of networks to generate trust and solve collective action problems is particularly salient when it comes to international cooperation between states, where majoritarian decision-making is less relevant and legitimate. For example, notwithstanding its current crises, the European Union (EU) is a political system that has historically been able to overcome differences and resolve controversies without leaving disappointed minorities behind. EU member states are diverse in terms of wealth, population sizes, domestic regulatory regimes and administrative cultures. Finding agreement on controversial issues therefore often requires protracted discussions in which state representatives communicate their policy demands and listen to those of others. How the relevant policy networks operate is likely to have important implications for decision-making in such a system.

We examine network relations in the Council of the European Union (formerly referred to as the Council of Ministers), which is the most powerful decision-making body in the EU. The research design brings together the datasets from two major studies of decision-making in the EU. The first study examined the network relations between each pair of member states in the main subcommittees of the Council at three time points: 2003, 2006 and 2009 (Naurin and Lindahl, 2010). The second study focused on decision-making on controversial legislative proposals in the period 1998-2008, and includes information on the policy positions of each of the member states on the issues raised by selected proposals (Thomson et al., 2006; Thomson, 2011).

Using the stochastic actor-oriented model (SAOM) (Snijders, van de Bunt and Steglich, 2010), we analyze the network evolution of cooperative ties among EU member states in several Council committees: the high-level coordinating committee Coreper I and five policy-oriented 
working-group committees (dealing with agriculture, environment, taxation, justice, and competition). We examine whether the networks change over time in line with theoretical propositions concerning preference similarity and network structures. Rather than focusing on dyadic ties, SAOM explicitly specifies and models actors' utilities in a network setting, and thus deals appropriately with the interdependencies among our observations. Moreover, the actor-oriented approach of SAOM allows us to combine analyses of multiple policy-oriented committees and compare them with Coreper I.

We find that both preference similarity and the existence of shared partners increase the chances of cooperation. The evidence suggests that to some extent the strength of these effects depend on the political-strategic context. Homophily, in terms of preference similarity, affects the evolution of the network relations both in the high-level committee of Coreper I and in some of the policy-specific working groups. The effect of preference similarity is stronger in the policy-oriented working groups than in Coreper for the committees for which we have comparable data with Coreper. Social network relations based on transitive and facilitating links are important in explaining network evolution at all levels of the Council.

\section{Policy preferences as explanations of network ties}

Policy preferences feature prominently in some explanations of network ties (König and Bräuninger, 1998; Carpenter, Esterling and Lazer, 2004; Berardo and Scholz, 2010; Leifeld and Schneider, 2012). Research on lobbying, for example, has found that two actors are more likely to form a tie if their preferences are more congruent (Carpenter, Esterling and Lazer, 2004, p. 224-5). Signaling theory examines interest groups' decisions to initiate influence attempts and elected representatives' decisions to receive such influence based on, among other factors, the congruence between interest groups and representatives' interests (Austen-Smith and Wright, 1992; Austen-Smith, 1993; Ainsworth, 1993). The game played between interest groups and representatives is defined by interest groups' aim of maximizing their influence on policies and 
representatives' aim of identifying policies that maximize their chances of reelection. Ainsworth's (1993) model focuses on the costs that lobbyists incur when convincing representatives that their interests are aligned to those of representatives' constituents. Austin-Smith and Wright's (1992) model examines how representatives select the lobbying attempts that congrue with their constituents' interests. Interest groups have incentives to engage in counteractive lobbying to convince decision makers who hold different preferences from theirs, at least under certain conditions. But decision makers always prefer to receive information from lobbyists whose preferences are similar to theirs. Signaling theory therefore features the actions of both senders and recipients of information in its explanation of network ties between actors.

Studies of interest groups are relevant to our focus in that they highlight the relevance of similarities between actors' preferences to explaining the occurrence of ties. Our focus on ties between decision makers in the committees of the Council of the EU is distinct in that all of the actors we consider have at least some voting power. Nonetheless, contacts among decision makers also take place in settings with imperfect information, where the actors hold different levels of information regarding the consequences of different policies in response to a policy problem. One important signal regarding the trustworthiness of information from other committee members is the extent to which those members had congruent preferences on similar issues in the past.

Existing studies also suggest that the impact of preference similarity on cooperative ties varies across different settings. Leifeld and Schneider (2012) argue that the impact of preference similarity may be qualified by the type of information exchange that takes place. Preference similarity is likely to be important when actors coordinate on political-strategic issues, such as forming instrumental alliances in order to influence policy outcomes. In such situations, coordination is more likely to be beneficial when the actors share similar policy goals. This is also a key proposition of the advocacy coalition framework (Sabatier and Weible, 2007).

For actors who are in a more deliberative mode, by contrast, exchanging technical and scientific information in order to reduce complexity and increase their understanding of the issues that are on the table, a different dynamic may arise. When the network relations concern 
exchange of technical information, actors are more likely to turn to well informed others, who may not necessarily be allies with respect to policy goals. For that reason, Leifeld and Schneider (2012, p. 735) argue that the effect of preference similarity is less pronounced in networks in which the actors are focused on exchanging technical information, than in networks in which the actors are focused on political and strategic issues.

In sum, preference similarity strongly predicts the emergence of cooperative ties in settings where the political stakes are high, but less so in settings where actors engage mainly in technical discussions. The supposed relevance of preference similarity to settings in which the political stakes are high might lead us to expect greater effects in the high-level Coreper committee than in the policy-specific committees. However, the policy-specific committees are also where the majority of controversies are resolved and therefore the level at which states have greatest opportunities to influence policy outcomes. This might lead us to expect stronger effects of preference similarity on network evolution in the policy-specific working groups. We therefore explore whether preference similarity influences network evolution in the Council and how the strength of the homophily mechanism varies across the different levels of the Council's hierarchy.

\section{Network characteristics as explanations of ties}

Social capital theory holds that actors are embedded in complex social relations, which connect actors to each other via multiple paths, and that these social structures condition trust (Coleman, 1988; Putnam, 1993; Schneider et al., 1997). These links are more than just channels through which actors send information; they also support mechanisms through which actors monitor and sanction each other in the event of behaviour that violates social norms and creates collectively sub-optimal outcomes. Burt (2005) refined and formalized concepts from social capital theory with a view to identifying measurable aspects of social capital, notably the concepts of bridging and bonding social capital. Bridging ties are ties that connect otherwise unconnected sets of actors, even filling structural holes. Bonding ties connect otherwise connected sets of actors with 
new reinforcing links Berardo and Scholz (2010)argue that such bonding ties help provide credible commitments in high-risk cooperation dilemmas.

In light of this, social capital theory suggests that existing ties and their patterns (i.e. network characteristics) predict future ties. Unlike preference similarity, which focuses on dependencies between a pair of actors, social capital theory highlights the dependencies between ties in the evolution of cooperative networks. In this study, we explore three types of network characteristics: reciprocity, triad, and hub.

\section{A Reciprocity}

Reciprocity is perhaps the most basic and well-studied network attribute. Reciprocity simply implies that actor $i$ is more likely to report a tie with actor $j$ if $j$ reports a tie with $i$. For many, reciprocity is key to promote and sustain the norms of coordination and cooperation among network members (e.g., Coleman, 1988; Putnam, 1993). Ostrom (1998) argues that when reciprocity prevails, network members are motivated to acquire a reputation for keeping promises and performing actions with short-term costs but long-term net benefits. Reciprocal ties, therefore, are regarded as a salient characteristic of networks with high levels of social capital.

The importance of reciprocity in international settings has been frequently emphasized. Neoliberal institutionalists argue that reciprocity is the main organizing principle that enables states to overcome collective action problems (Axelrod and Keohane, 1985). Since states enter games of cooperation repeatedly, reciprocity and the strategies associated with reciprocity, such as tit-for-tat, introduce effective sanctions and foster international cooperation under anarchy (Axelrod, 1984). Moreover, reciprocal linkages build mutually beneficial dependencies and obligations between the actors involved. Reciprocally connected actors become, at least to some extent, mutually dependent on each other for the supply of information and other forms of cooperation. In our following analysis, we expect that EU members tend to establish reciprocal cooperative ties over time. 


\section{B Triad}

Another important class of network characteristics is triadic relations. Research has revealed that local reciprocity alone is insufficient to maintain cooperation in large groups (Bloch, Genicot and Ray, 2007). Social pressure in the form of a common friend (i.e. a triadic relation) can effectively overcome this problem and make cooperation enforceable and renegotiation-proof (Jackson, Rodriguez-Barraquer and Tan, 2012). We therefore base our expectations on Carpenter, Esterling and Lazer's (2004, p. 227; also see Holland and Leinhardt, 1971; Fernandez and Gould, 1994; Wasserman and Faust, 1994) point of departure: "Following a long tradition in network analysis, the key social structural unit we use to measure the impact of the social structure on the ties between two actors is the triad". Berardo and Scholz (2010) also note that the triad is the simplest structure with which to model bridging and bonding elements of social capital.

More formally, triadic relations involve at least three actors. When considering the likelihood of a link between actors $i$ and $j$, we examine all possible third actors (each referred to as "actor $h$ "). We examine whether the presence of certain links between these third actors and actors $i$ and $j$ affect the likelihood of a link from $i$ to $j$. Since international cooperation can be directional, we distinguish between facilitating links and transitive links as depicted in Figure 1.

\section{[Figure 1 is about here.]}

Facilitating links. We expect to observe that actor $i$ is more likely to cooperate with actor $j$ if $i$ and $j$ are in similar structural positions with respect to third actors. For instance, there may be many third actors that cooperate with both $i$ and $j$. Facilitating links may reduce the costs of cooperation between $i$ and $j$. Facilitators may also provide a "common frame of reference" to $i$ and $j$ on policy matters (Carpenter, Esterling and Lazer, 2004, p. 228). Likewise, if there are many actors in the network with which both $i$ and $j$ are not linked, this may also promote a common frame of reference, since both will be insulated from the influence of the same third 
actors. $^{1}$

Transitive links. Our expectation is that actor $i$ is more likely to cooperate with actor $j$ if there are more third actors with transitive links that connect $i$ to $j$. Actor $h$ provides a transitive link from $i$ to $j$ if $i$ cooperates with $h$ and $h$ cooperate with $j$ (Figure 1). The importance of transitivity has long been observed in friendships at the individual level (Davis, 1967; Holland and Leinhardt, 1971), which formalizes the common wisdom that "friends of friends are friends". Ties that are embedded within transitive links increase the dependencies between the actors involved. This dependency increases the possibility of sanctioning non-cooperative behaviour. For instance, actor $i$ can cooperate with actor $j$ in the knowledge that it $(i)$ could report misbehaviour on the part of $j$ to $h$. Since $h$ also cooperates with $j$, it is likely that $j$ wishes to avoid such sanctioning behaviour. A related argument concerns the trustworthiness of information flowing from $j$ to $i$, which presumably conditions actor $i$ 's decision to cooperate with $j$ (Carpenter, Esterling and Lazer, 2004; Berardo and Scholz, 2010). If actor $i$ cooperates with $h$, this implies that $i$ is satisfied with the information it receives from $h$. If, as is the case in a transitive link, $h$ also cooperates with $j$, this implies that $h$ is also satisfied with the information it receives from $j$. This positive evaluation by $h$ of $j$ may increase the trust that $i$ has in the information provided by $j$, thereby increasing the likelihood of cooperation.

\section{Hub}

Finally, research on the development of network ties in other contexts has consistently found evidence of a "Matthew effect", whereby the rich get richer, which is also referred to as preferential attachment in network analysis (Barabási and Albert, 1999). The "hubs" in a network,

\footnotetext{
${ }^{1}$ This argument suggests that the presence of facilitators, or more generally similarity between actors in their structural positions, affect actors' policy positions. As mentioned above, since we are interested in the effects of both preferences and network structures, our measures of actors' policy positions should be taken before the time point at which we observe the network ties.
} 
which have many incoming network ties, tend to enjoy a cumulative advantage, in which these popular actors are more likely to be selected than unpopular ones. In international cooperation, such as that which takes place in the Council of the EU, a popular state with many partners is expected to attract more new partners than less popular states with fewer existing partners.

\section{Research design}

We integrate two major datasets on network relations (Naurin and Lindahl, 2010) and policy positions (Thomson et al., 2006; Thomson, 2011) in the EU. This gives us a unique opportunity to test both preference and network-based explanations of network ties. More details of the procedures followed and measures developed in these two studies can be found in the publications cited above. Here, we give a summary of the main points that are relevant to the present study.

\section{A Measuring cooperation networks}

Information on the network relations among member state representatives was obtained through a survey of officials from the representations of all member states to the EU in Brussels. Three surveys were conducted, in 2003, 2006 and 2009, which therefore gives data from both before and after the enlargements in 2004 and 2007. All representatives in eleven selected committees in the Council were approached for the interviews. Six of these committees are included in the present study due to data limitations (see Table 1). Both a high-level committee and lower-level working groups were included, involving a broad range of policy areas, ranging from economic policy to

justice and home affairs. The interviews were conducted by telephone. There was a high response rate in all three rounds: 81 percent in 2003, 84 percent in 2006 and 86 percent in 2009. In total, 618 member state representatives were interviewed: 130 in 2003, 231 in 2006 and 257 in 2009.

In all three surveys, the following question was asked: "Which member states do you most often cooperate with within your working group, in order to develop a common position?" On the basis of the respondents' answers to this question, we identify the network relations between 
member states. The question posed focuses respondents' attention on direct contacts with people from other member states in their working groups. Respondents were free to list other member states with which they cooperated, and typically mentioned between three and five others. ${ }^{2}$ Their answers revealed interesting patterns of cooperation evolution for each surveyed committee.

\section{[Figure 2 is about here.]}

Figure 2 depicts how the cooperation network in Coreper I evolved from 2003 to 2009. The arrow from a first member state to a second one indicates that a representative of the first state said that he or she cooperates with the second state. The figures show that while in 2003 the cooperation network was relatively sparse, the network density increased in 2006 after ten new members joined and appeared to stabilize at that level. The cooperation networks suggest that reciprocal ties are perhaps not as prevalent as suggested in the earlier literature. Yet we can find triadic relations do contribute to cooperation diffusion. For example, Portugal and Greece are isolated from the cooperative network in 2003 , but they are included in multiple triadic relations in 2006. Finally, we can also observe some cooperation "hubs" throughout the time. France, Germany, and UK consistently receive and send many cooperative ties, suggesting strong popularity effects.

\section{[Table 1 is about here.]}

\footnotetext{
${ }^{2}$ It should be noted that the question refers to the other member states with which the respondent cooperates most often. Directed cooperative ties $(i$ indicating cooperation with $j$, but not vice versa) can be interpreted as directed expressions of willingness to cooperate and the importance of the relationship to the respondent state. For example, a directed non-reciprocated tie between Slovenia and the UK reflects that Slovenia has to seek cooperation from UK to reach a common position (i.e. a directed willingness to cooperate), or simply reflects the fact that the UK representative cooperates more often with Germany and Sweden, and possibly attaches greater importance to those relationships, than to the relationship with Slovenia. The directed tie, therefore, indicates that the Slovenia-UK cooperation is valued more highly by the Slovenian representative than the UK representative.
} 
Table 1 presents detailed network statistics for each cooperation network across three waves of the survey. We identify the ratio of triads closed by facilitating and transitive links respectively. Since the outcomes of both types of network closure are structurally equivalent, we divide the number of such closed triads by the number of triads where facilitators are present to arrive at the facilitation index, and by the number of triads where an indirect relation exist to arrive at the transitivity index. These indices range from a low of 0.25 in 2009 for Coreper I to a high of 0.60 in 2003 also for Coreper I. These conditional tie probability indices are larger than the density of the network, which is the unconditional tie probability between two randomly sampled countries in the network. As such the indices indicate that facilitators and indirect relations make ties more likely.

\section{B Member states' policy positions}

We construct measures of the preference similarity between each pair of member states' policy positions based on a study of decision-making on controversial legislative proposals in the period 1998-2008 (Thomson et al., 2006; Thomson, 2011). For a selected 125 legislative proposals, a team of researchers held face-to-face semi-structured interviews with key informants to obtain information on the controversies raised by these proposals and EU actors' policy positions on

these controversies. Key informants were asked to "indicate the policy alternative initially favored by each stakeholder after the introduction of the proposal and before the Council formulated its common position".

\section{[Table 2 is about here.]}

Table 2 presents an illustration about how policy positions are drawn from the legislative proposal on sugar sector reform. This was the first important reform of agricultural policy that took place after the 2004 enlargement. Eleven semi-structured interviews were held with experts from the member states' permanent representations, the Commission and the European Parliament. The main controversial issue raised by this proposal was the size of the price cut, which would reduce EU subsidies for sugar production. Member states took six distinct policy 
positions on this issue, ranging from Poland's support for keeping the then current level of subsidy for sugar production, to Denmark, Estonia and Sweden's demand for a very large cut in the intervention price and level of subsidy. Other member states took positions between these alternatives. The second issue in the sugar case is the extent to which producers should be compensated for the price cut. The third issue raised by the sugar sector reform concerned the sequencing of cuts in production quotas for different types of sugar.

The dataset contains detailed information on member states' policy positions on each of the 125 selected legislative proposals, like that summarized in Table 2 . These 125 proposals raised 331 controversial issues, which were described in detail by key informants. Legislative proposals were selected according to three criteria: the time period, the type of legislative procedure and the level of political importance. Regarding the time period, legislative proposals were included if they were on the Council's agenda in the years 1999 and/or 2000, or were discussed for the first time in the Council after the 2004 enlargement. Legislative proposals introduced up to June 2008 were included in the post-2004 study. Concerning the decision-making procedure, the selected legislative proposals were subject to either the consultation or the codecision procedures, the two most commonly used procedures. Regarding political importance, the selection was restricted to proposals on which there was an indication of at least some political importance and controversy. The policy areas represented most prominently in the selection are agriculture (twenty-six proposals), internal market (eighteen), Justice and Home Affairs (eleven) and fisheries (fourteen). However, many other policy areas are present too.

Information on controversial issues and actors' initial positions on these issues was collected in 349 semi-structured interviews with key informants. These interviews typically lasted between 60 and 90 minutes. The key informants were selected for their knowledge of the detail of the dossiers under investigation. Individuals with different institutional affiliations were interviewed. The 47 Commission officials interviewed were responsible for drafting the proposals and/or monitoring the subsequent discussions. The 236 officials from the permanent representations were the responsible desk officers. The 45 individuals from the EP were either MEPs or their 
assistants. A further nine interviewees worked in the Council secretariat and twelve in interest groups.

These data on member states' policy positions on controversies raised by legislative proposals are the most appropriate data available for our purposes of testing the preference-based explanation of network ties. The obvious alternatives, member states' voting behaviour and national governments' ideological positions, are not appropriate. Decision-making in the Council usually proceeds by consensus, rather than voting. Moreover, voting takes place after the Council formulates its common position, while the temporal focus of the network data is before the common position. National governments' ideological positions do not clearly structure member states' policy preferences in the Council (Thomson, 2011). Rather, member states' policy positions tend to coalesce by policy sector and on an issue specific basis. Therefore, measures that are based on the specific controversies dealt with in the Council are most relevant.

\section{Merging the two datasets}

We identified six committees from the network study with which we could match the positional data from the decision-making study. First, Coreper I was included in all three waves of the network study, 2003, 2006 and 2009. Coreper I is a high-level coordinating committee, composed of the deputy ambassadors of the member states EU representations, which deals with legislative proposals from all policy areas included in the decision-making study. Therefore, we matched the network relations in a given year with measures of policy agreement based on legislative proposals that were introduced in previous years. Specifically, we matched the 2003 network data with legislative proposals that were on the Council's agenda in 1999 and/or 2000. We matched the 2006 network data with legislative proposals introduced in the period 2003-2005. This timing obviously precludes the possibility that our positional data are influenced by the network data.The dyadic policy agreement measure is the proportion of controversial issues raised by the relevant set of legislative proposals on which each pair of member states in question took the same policy position. Our dyadic scores of preference similarity in Coreper I are presented in Figure 3, with 
the shaded shares of pies indicating the degree of preference similarity.

\section{[Figure 3 is about here.]}

The other five Council committees we include in this study are policy-specific working groups dealing with more technical issues and preparing the ground for the meetings of the Coreper and the ministers. Network data from each committee in a given year were matched with legislative proposals from the relevant policy area in previous years. We included as many committees and years as possible, but were limited by the exclusion of some committees from some years of the network study and by the exclusion of some policy areas from some years of the decision-making study. As well as Coreper I, the following five committees are included with network data on at least some years: 1) the working group on agriculture in 2003, 2006 and $2009 ;^{3}$ 2) the working group on environmental policy in 2006 and 2009; 3) the working group on taxation in 2003, 2006 and 2009; 4) the working group on justice and home affairs (Article 36 committee) in 2006 and 2009; and 5) the working group on competition from 2006 and 2009. ${ }^{4}$ The merged dataset contains 5,694 observations (ordered dyads of member states) for which we have information on all relevant explanatory variables.

\footnotetext{
${ }^{3}$ The network study actually includes two related agricultural working groups, the special committee on agriculture and the agriculture working group, which contain very similar network ties. For presentation purpose, we only present analyses based on the agriculture working group. For additional analyses of the special committee, please see Supporting Information.

${ }^{4}$ The decision-making study did not include environmental proposals of relevance to the 2003 network data. The network study did not include justice and home affairs or competition in 2003. The network study also included several other committees for which no relevant positional data from the decision-making study were available, such as the working group on security issues. These network data were excluded from the present study.
} 


\section{The network model}

This study employs stochastic actor-oriented models (SAOM) to model the dynamic evolution of cooperation networks (Snijders, 2005; Snijders, van de Bunt and Steglich, 2010).Compared to other longitudinal network models (e.g., Hanneke, Fu and Xing, 2010; Desmarais and Cranmer, 2012), SAOM is explicitly actor oriented, and assumes that actors change their ties as a consequence of optimizing an objective function. Based on their perceived interests (i.e. objective functions), each actor decides whether or not to change an outgoing relationship by creating or dropping a tie. The network changes are results of simultaneous strategic choices made by individual actors to maximize their utilities. SAOM therefore deals appropriately with the interdependencies in our merged dataset.

Specifically, SAOM estimates a range of effects on actors' decisions, including effects associated with network structures such as those depicted in Figure 2, and characteristics of egos (i.e. the actors taking the decisions to create or dissolve links), alters (i.e. the actors to which egos consider linking), and dyads (i.e. pairs of actors). Our key variable, policy agreement, is a characteristic of dyads. The odds that an actor will change its outgoing ties is modelled by the objective function. Actors optimize their objective functions in the sense that they have a higher probability of forming ties that increase the value of their objective functions. Actors perform this optimization while being constrained by the network structure in which they find themselves. Because of the dynamic nature of the model, this constraining network structure encompasses the changes made earlier by other actors, such that actors constrain each other in a dynamic feedback process. The addition of random effects to the objective function allows us to account for residual preferences. The dynamic feedback between actors' decisions is incorporated into the simulation procedure discussed below. The objective function for actor $i$ is defined as a weighted sum of effects,

$$
f_{i}(\beta, x)=\sum_{k} \beta^{k} s_{i}^{k}(x)
$$

where the $s_{i}^{k}(x)$ are the set of effects, which in our application include reciprocal, facilitating and 
transitive links, as well as preference similarity. The terms $\beta^{k}$ are the parameters to be estimated.

To test both preference- and network-based explanations, we examine the impacts of various dyadic and network factors. The effect of policy agreement on tie formation is included as a dyadic explanatory variable. If $p_{i j}$ stands for the agreement of countries $i$ and $j$ in policy and $\bar{p}$ for the mean of $p_{i j}$, then the effect,

$$
s_{i}^{\text {policy-congruence }}=\sum_{j} x_{i j}\left(p_{i j}-\bar{p}\right),
$$

expresses the tendency of these countries to select each other based on this agreement. A positive $\beta^{\text {policy-congruence }}$ estimate then suggests that country $i$ is more likely to initiate cooperative ties to countries with whom country $i$ shares higher preference similarity.

To capture the impacts of reciprocity, we include the following effect,

$$
s_{i}^{\text {reciprocity }}=\sum_{j} x_{i j} x_{j i}
$$

which is defined as the number of reciprocated ties. We expect a positive and significant $\beta^{\text {reciprocity }}$ when states reciprocate others' favors and cooperative initiatives.

We operationalize states' tendency to form transitive links by including:

$$
s_{i}^{\text {transitive-triad }}=\sum_{j, h} x_{i j} x_{i h} x_{h j}
$$

where $i \neq j \neq h$. Similarly, we incorporate the occurrence of facilitating links by adding the term,

$$
s_{i}^{\text {facilitating-triad }}=\sum_{j, h} x_{i j} x_{h i} x_{h j}
$$

which incorporates the impact of additional facilitators $h$ on tie creation between actors $i$ and $j$, as depicted in Figure 1. In general, positive estimates of above two effects suggests that states sharing common cooperation partners are more likely to form cooperative ties with each other. 
To account for the distributions of incoming and outgoing ties, we include two further effects. First, the indegree popularity effect is defined as,

$$
s_{i}^{\text {indegree-popularity }}=\sum_{j} x_{i j} \sum_{k} x_{k j}
$$

This effect is also referred to as the popularity of alter effect. It is the sum of the indegrees of the other actors to which $i$ is tied. A positive estimate represents the tendency for actors to choose other actors that are already popular cooperation partners in the network. Second, the outdegree activity effect is defined as,

$$
s_{i}^{\text {outdegree-activity }}=\sum_{j} x_{i j} \sum_{k} x_{i k}
$$

This effect expresses the variability in countries' tendency to send ties to few or many other countries. A positive estimate would indicate that those who already send many ties have an increased tendency to send even more ties.

Finally, to control for the overall density of the cooperation networks, we include the outdegree effect,

$$
s_{i}^{\text {outdegree }}=\sum_{j} x_{i j},
$$

which reflects the average tendency of actors to have ties with random others in the network and as such functions as an intercept in the model. Negative $\beta^{\text {outdegree }}$ estimate suggests a low expected odds of a link for a tie within a dyad of actors (i.e., network density below 50\%), whereas a positive estimate indicates high expected odds of a link (i.e., network density above $50 \%)$.

With the various dyadic and network effects (i.e., $s_{i}^{k}(x)$ ), we are able to specify actors' objective function (i.e., Eq. 1). To estimate the corresponding estimates $\beta^{k}$, SAOM assumes that the process of network evolution unfolds in continuous time, and that the observed moments are snapshots of this process. SAOM then treats the changing network as the result of a Markov process in which the current state of the network is a dynamic constraint on its development. This enables SAOM to estimate the set of coefficients that best fit the observed changes in the network 
over time. Basically, $\beta^{k}$ is estimated by minimizing the difference between the observed and the expected values. Since SAOM shares key characteristics with logistic regression, we can calculate t-statistics from estimated coefficients and standard errors. ${ }^{5}$

Besides its actor-based framework, we also prefer SAOM in this study for another two reasons. First, SAOM can explicitly take EU enlargement into account. The EU enlarged from 15 members in 2003 to 27 in $2007 .{ }^{6}$ SAOM explicitly models such changes to the composition of the network and treats the new actors separately from the random missing data. ${ }^{7}$ This makes SAOM particularly appropriate for our study.

Second, the Council of the EU includes several policy-specific working groups within the same institution, which are therefore not independent committees. Rather than treating them simply as independent case studies, it is desirable to conduct parallel studies of these specific groups and combine them in a pooled analysis. This suggests a multilevel network analysis, where the micro level is the network analysis within each single working group, and the macro level is the combination of these multiple network studies (Snijders and Baerveldt, 2003). SAOM solves this problem by assuming the observed cooperation networks of specific policy committees are samples from a population, a population of cooperation networks of all policy-specific committees. The true parameter values are a random sample from the parameter values in a population of policy-specific committees. We use SAOM to calculate the distribution of these true parameters in the population of policy-specific committees. This produces more generalizable findings and provides an intuitive way to compare Coreper I with the policy-specific committees taken together.

${ }^{5}$ For details about the estimation procedure, see Snijders, van de Bunt and Steglich (2010) and Ripley et al. (2015).

${ }^{6}$ Our data precede the accession of Croatia to the EU in 2013.

${ }^{7}$ For details about SAOM treatments of the composition change and random missings, see Ripley et al. (2015). 


\section{Results}

We begin by testing the preference and network-based explanations in the higher-level coordinating committee, Coreper I. We then turn to the policy-oriented committees that were surveyed in all three waves (agriculture, environment, and taxation) and conduct multilevel network analysis on these three committees. Finally, we extend our analysis to two other policy-oriented committees (justice and competition) that were surveyed only in the last two waves. For each set of analyses, we measure policy preference similarity in accordance with the policy domain of each committee.

Table 3 presents our SAOM analyses of cooperation evolution in Coreper I. Given the interdependent nature of cooperation networks, different network statistics can be highly sensitive to each other. Recognizing the potential problem of collinearity, we present Model 1 with only one basic network effect (reciprocity), and then incorporate preference similarity, triad, and hub effects in a stepwise manner. The estimate for a given network effect in SAOM is the log odds ratio of the respective probabilities that an actor will choose to initiate a cooperative tie. This makes interpretations of SAOM estimates similar to those of multinomial logistic regression. For example, in Model 1 the SAOM estimate of the reciprocity effect is 0.714 , corresponding to an odd ratio of 2.04 (i.e., $e^{0.714}=2.04$ ). This suggests that with an existing cooperative tie from state $j$ to $i$, the probability of forming a reciprocal cooperative tie will be increased by a factor of 2.04.

\section{[Table 3 is about here.]}

Both the policy preference and network characteristics contribute to cooperation in Coreper

I. First, the preference similarity is consistently significant and positive in Models 2 to 4, although its substantive impact declines as more network effects are included. Second, our analysis confirms the earlier literature on the importance of reciprocity in cooperation emergence (e.g., Coleman, 1988; Putnam, 1993; Ostrom, 1998). Third, we find mixed evidence for the two triadic effects. While the effects of transitive links become statistically insignificant as more effect effects are included, the impact of facilitating links turn out to be even stronger. Specifically, in Model 4 the SAOM estimate of facilitating links is 0.313 . This means that when two states share 
five common friends (i.e. facilitators) rather than none, their probability of forming a tie is greater by a factor of 4.78 (i.e., $e^{0.313 \times 5}$ ). we find both forms of hub effects (outdegree activity and indegree popularity) are statistically significant in Model 4. However, we should be cautious in assessing the substantive importance of outdegree activity. A very active state which initiated five cooperative ties in the past compared to none, for example, has a greater probability of forming another tie, but only by a factor of 1.32 . In contrast, a popular state, which received five ties rather than none enjoys considerable cumulative advantage in future cooperation, by a factor of 3.34 .

\section{[Figure 4 is about here.]}

As an agent-oriented approach, SAOM uses simulation intensively, and the simulated networks generated in the estimation process provide a convenient way to compare the relative goodness of fit of different models. Based on 10,000 simulated networks for each of the four stepwise models in Table 3, Figure 4 plots how well they fare against our observed cooperation networks in Coreper I. Specifically, we use the distribution of outdegree (i.e. proposed cooperative ties) and indegree (i.e. received cooperative ties) as the benchmark statistics. The dots denote the corresponding statistics for different outdegrees and indegrees, and the solid lines help reveal the general shapes of indegree and outdegree distributions. For simulated networks, we plot the upper and lower bounds in dashed lines and their $90 \%$ intervals in shadowed regions. The complete model (i.e. Model 4) performs best across both indegree and outdegree, with the solid line both mostly covered by the shadowed regions and completely enclosed by the dashed lines. In our following analyses, therefore, we present the results of a basic model and the complete model only.

\section{[Table 4 is about here.]}

Table 4 presents the analysis of three policy-oriented committees, and two important findings stand out from this. First, preference similarity consistently contributes to cooperation in each of the three committees. Moreover, its substantive impacts seem to be larger than those in Coreper I. Second, there is some noteworthy variation in other network effects such as triad and hub effects. In the environment committee while both triad effects (i.e. transitive and facilitating links) are 
important, there are no significant effects of outdegree or indegree popularity (Model 8). This suggests that environmental cooperation in the Council is not driven by a few active or popular states. Instead, previously unconnected members are bridged by transitive and facilitating states, and the whole network becomes increasingly "flattened." By contrast, cooperation in the agriculture committee exhibits the strongest hub effects but weakest triad effects (Model 6). Finally, the committee on taxation policies occupies the middle ground with moderate triad and popularity effects (Model 10).

\section{[Figure 5 is about here.]}

We combine the analysis of these three committees in multilevel network models as discussed above (Models 11 and 12), and the estimates of these models can be interpreted as the "true parameters" of a generic policy-oriented network. A comparison of these models with the models of Coreper in Table 3 reveals very similar network effects. However, there is a marked difference regarding the impact of preference similarity. To aid our comparison, Figure 5 presents the expected impacts of preference similarity on the formation of ties in Coreper I and the generic policy-oriented committee. The steeper slope in Figure 5.b indicates that preference similarity has a much greater impact on the formation of ties in policy-oriented committees than in Coreper.

\section{[Table 5 is about here.]}

Finally, we extend the network analysis to cooperation in the justice and competition committees, and the results are presented in Table 5. Given that the data for these committees do not cover the three time points, any comparative inferences we might draw are less certain. Two important network effects are significant in the evolution of the networks in these committees, namely facilitating triads and indegree popularity. However, neither reciprocity nor preference similarity remain significant in the full models. Two factors may help explain these variations. First, compared to the previous analyses, we have only limited data about these two committees, which were surveyed in 2006 and 2009 only. Second, as suggested in our discussion of multilevel network analysis, there may be some systematic or random differences between various policy-specific subcommittees. The absence of significant effects of preference similarity in these 
two committees suggest that we should be cautious in inferring that preference similarity has a significantly greater effect in the policy-specific committees than in Coreper, as the comparison of the multilevel model (Model 12) with the Coreper model (Model 4) implies.

\section{Discussion}

Our findings demonstrate that both network characteristics and preference similarity affect cooperative relations between political actors. We examined several mechanisms through which the networks in which actors are embedded affect their propensity to cooperate with others. The evidence indicated that in the Council of the EU, transitive and facilitating links have significant positive effects on the likelihood of a tie being established and maintained. This means that actor $i$ is more likely to cooperate with $j$ if 1) there are many third actors with whom $i$ cooperates and who also cooperate with $j$ (transitivity), and 2) if $i$ and $j$ are in a similar structural position regarding their incoming ties, such that there are many third actors who say they cooperate with both $i$ and $j$ (facilitators).

Social capital theory provides the insight that network relations bring significant benefits to the social system as a whole and its members. Social systems held together with dense networks of transitive and facilitating ties have social capital that enables them to overcome collective action problems (Coleman, 1988; Putnam, 1993). Similarly, in neoliberal institutionalist theory, reciprocal ties create interdependencies that help states overcome collective action problems (Axelrod, 1984). Actors who are embedded in network relations have opportunities to monitor and sanction their cooperation partners for dissembling. In systems with high levels of social capital, recalcitrant actors face retaliation by the severing of reciprocal links and/or links from third actors. Researchers in other contexts have arrived at similar conclusions regarding the effects of network structures on relations among interest groups and between interest groups and public agencies (e.g., Carpenter, Esterling and Lazer, 2004; Berardo and Scholz, 2010). Our findings indicate that these relationships also hold for international decision makers in the most 
powerful legislative body of the European Union.

Policy agreement between two actors positively affects the likelihood of a tie between them even after controlling for network characteristics. Like our findings on network characteristics, several previous studies also found this pattern in other contexts, with respect to interactions among interest groups and between interest groups and public agencies (e.g., Bauer, de Sola Pool and Dexter, 1972; Laumann and Knoke, 1987; König and Bräuninger, 1998; Carpenter, Esterling and Lazer, 2004). The positive effect of preference similarity varies somewhat across the committees we examined. We found the strongest effect of preference similarity in three policy-oriented subcommittees (agriculture, environment and taxation), a weaker but still significant effect in the high-level Coreper committee, but no robust and significant effect in two policy-oriented subcommittees for which we have more limited data. Leifeld and Schneider (2012) suggest that preference similarity is more important in politically charged settings where actors are concerned primarily with influencing policy outcomes and less relevant in settings in which actors exchange technical information. Our mixed findings with respect to the effect of preference similarity indicate that the distinction between the political and the technical is blurred, particularly in the regulatory intense environment of EU decision-making.

The research presented here also highlights the political reasons why the prospect of the United Kingdom leaving the EU poses an enormous challenge for both the UK and the remaining EU members. The UK is deeply embedded in the political system of the EU, and nowhere is this more evident than in the preference alignments and cooperation networks in the Council. Contrary to what some campaigners in the Leave side of the referendum campaign claimed, the best evidence we have on preference similarity among member states shows clearly that the UK has not been a preference outlier. On the contrary, the UK's policy positions on controversial issues show high levels of agreement with the positions of a broad range of other EU member states. Moreover, the UK occupies some of the most central positions in the cooperation networks we examined. The strength of these political ties, in addition to the economic, legal and cultural connections, means that extracting the UK from the EU will be a wrench for both the UK and the 
other member states. The analyses also revealed the significance of indirect ties between actors for the maintenance and development of cooperative relations. This implies that the departure of the UK will also affect the cooperative relations between the remaining states. As a large state with many incoming and outgoing ties, the UK connects many other pairs of states that are either weakly connected or unconnected to each other. The departure of the UK will therefore be a test of the strength of the social capital among the remaining members in years to come. 


\section{References}

Ainsworth, Scott. 1993. "Regulating Lobbyists and Interest Group Influence.” Journal of Politics 55:41-56.

Austen-Smith, David. 1993. "Information and Influence: Lobbying for Agendas and Votes." American Journal of Political Science 37(3):799-833.

Austen-Smith, David and John R. Wright. 1992. "Competitive Lobbying for a Legislator's Vote." Social Choice and Welfare 9(3):229-257.

Axelrod, Robert. 1984. The Evolution of Cooperation. New York, NY: Basic Books.

Axelrod, Robert and Robert O. Keohane. 1985. "Achieving Cooperation under Anarchy: Strategies and Institutions." World Politics 38(1):226-254.

Barabási, Albert-László and Réka Albert. 1999. "Emergence of Scaling in Random Networks." Science 286(5439):509-512.

Bardach, Eugene. 1998. Getting Agencies to Work Together: The Practice and Theory of Managerial Craftsmanship. Washington, DC: Brookings Institution Press.

Bauer, Raymond A., Ithiel de Sola Pool and Lewis Anthony Dexter. 1972. American Business and Public Policy: The Politics of Foreign Trade. 2nd ed. Chicago, IL: Aldine Atherton.

Berardo, Ramiro and John T. Scholz. 2010. "Self-Organizing Policy Networks: Risk, Partner Selection, and Cooperation in Estuaries.” American Journal of Political Science 54(3):632-649.

Bloch, Francis, Garance Genicot and Debraj Ray. 2007. "Reciprocity in Groups and the Limits to Social Capital." American Economic Review 97(2):65-69.

Burt, Ronald S. 2005. Brokerage and Closure: An Introduction to Social Capital. Oxford and New York: Oxford University Press.

Carpenter, Daniel P., Kevin M. Esterling and David M. J. Lazer. 2004. "Friends, Brokers, and Transitivity: Who Informs Whom in Washington Politics?” Journal of Politics 66(1):224-246.

Coleman, James S. 1988. "Social Capital in the Creation of Human Capital." American Journal of Sociology 94:S95-S120.

Davis, James A. 1967. “Clustering and Structural Balance in Graphs.” Human Relations 20(2):181-187.

Desmarais, Bruce A. and Skyler J. Cranmer. 2012. "Micro-Level Interpretation of Exponential Random Graph Models with Application to Estuary Networks." Policy Studies Journal 40(3):402-434.

Feiock, Richard C. and John T. Scholz. 2009. Self-Organizing Federalism: Collaborative Mechanisms to Mitigate Institutional Collective Action Dilemmas. Cambridge and New York: Cambridge University Press. 
Fernandez, Roberto M. and Roger V. Gould. 1994. "A Dilemma of State Power: Brokerage and Influence in the National Health Policy Domain." American Journal of Sociology 99(6):1455-1491.

Freeman, Linton C. 1978. "Segregation in Social Networks." Sociological Methods \& Research 6(4):411-429.

Gerber, Elisabeth R., Adam Douglas Henry and Mark Lubell. 2013. "Political Homophily and Collaboration in Regional Planning Networks." American Journal of Political Science 57(3):598-610.

Hanneke, Steve, Wenjie Fu and Eric P. Xing. 2010. "Discrete Temporal Models of Social Networks.” Electronic Journal of Statistics 4:585-605.

Heclo, Hugh. 1978. Issue Networks and the Executive Establishment: Government Growth in an Age of Improvement. In The New American Political System, ed. Anthony King. Washington, DC: American Enterprise Institute pp. 87-124.

Henry, Adam Douglas, Mark Lubell and Michael McCoy. 2011. "Belief Systems and Social Capital as Drivers of Policy Network Structure: The Case of California Regional Planning." Journal of Public Administration Research and Theory 21(3):419-444.

Holland, Paul W. and Samuel Leinhardt. 1971. "Transitivity in Structural Models of Small Groups." Comparative Group Studies 2:107-124.

Jackson, Matthew O. 2010. Social and Economic Networks. Princeton, NJ: Princeton University Press.

Jackson, Matthew O., Tomas Rodriguez-Barraquer and Xu Tan. 2012. "Social Capital and Social Quilts: Network Patterns of Favor Exchange.” American Economic Review 102(5):1857-1897.

König, Thomas and Thomas Bräuninger. 1998. "The Formation of Policy Networks: Preferences, Institutions and Actors' Choice of Information and Exchange Relations." Journal of Theoretical Politics 10(4):445-471.

Knoke, David, Franz U. Pappi, Jeffrey Broadbent and Yutaka Tsujnaka. 1996. Comparing Policy Networks. Labor Politics in the US, Germany and Japan. Cambridge and New York: Cambridge University Press.

Laumann, Edward O. and David Knoke. 1987. The Organizational State: Social Choice in National Policy Domains. Madison, WI: University of Wisconsin Press.

Leifeld, Philip and Volker Schneider. 2012. "Information Exchange in Policy Networks." American Journal of Political Science 56(3):731-744.

McPherson, Miller, Lynn Smith-Lovin and James M. Cook. 2001. "Birds of a Feather: Homophily in Social Networks." Annual Review of Sociology 27:415-444.

Naurin, Daniel and Rutger Lindahl. 2010. "Out in the Cold? Flexible Integration and the Political Status of Euro Opt-Outs." European Union Politics 11(4):485-509. 
Ostrom, Elinor. 1998. "A Behavioral Approach to the Rational Choice Theory of Collective Action." American Political Science Review 92(1):1-22.

Putnam, Robert D. 1993. Making Democracy Work: Civic Traditions in Modern Italy. Princeton, NJ: Princeton University Press.

Ripley, Ruth M., Tom A. B. Snijders, Zsofia Boda, András Vörös and Paulina Preciado. 2015. Manual for RSiena. University of Oxford: Department of Statistics, Nuffield College.

Sabatier, Paul A. and Christopher M. Weible. 2007. The Advocacy Coalition: Innovations and Clarifications. In Theories of the Policy Process, ed. Paul. A. Sabatier. Boulder, CO: Westview Press pp. 189-220.

Schneider, Mark, Paul Teske, Melissa Marschall, Michael Mintrom and Christine Roch. 1997. "Institutional Arrangements and the Creation of Social Capital: The Effects of Public School Choice." American Political Science Review 91(1):82-93.

Snijders, Tom A. B. 2005. Models for Longitudinal Network Data. In Models and Methods in Social Network Analysis, ed. Peter J. Carrington, John Scott and Stanley Wasserman. Cambridge and New York: Cambridge University Press pp. 215-247.

Snijders, Tom A. B. and Chris Baerveldt. 2003. "A Multilevel Network Study of the Effects of Delinquent Behavior on Friendship Evolution." Journal of Mathematical Sociology 27(2/3):123-151.

Snijders, Tom A. B., Gerhard G. van de Bunt and Christian E. G. Steglich. 2010. "Introduction to Stochastic Actor-Based Models for Network Dynamics." Social Networks 32(1):44-60.

Thomson, Robert. 2011. Resolving Controversy in the European Union: Legislative Decision-Making Before and After Enlargement. Cambridge: Cambridge University Press.

Thomson, Robert, Frans N. Stokman, Christopher H. Achen and Thomas König. 2006. The European Union Decides. Cambridge: Cambridge University Press.

Thurner, Paul W. and Martin Binder. 2009. "European Union transgovernmental networks: The emergence of a new political space beyond the nation-state?" European Journal of Political Research 48(1):80-106.

Wasserman, Stanley and Katherine Faust. 1994. Social Network Analysis: Methods and Applications. Cambridge and New York: Cambridge University Press. 
Table 1: Descriptive statistics

\begin{tabular}{cccccccccc}
\hline \hline & size & response & density & reciprocity & transitivity & facilitation & degree, $\mu$ & in, $\sigma$ & out, $\sigma$ \\
\hline $\begin{array}{c}\text { Coreper I } \\
2003\end{array}$ & 15 & 0.60 & 0.17 & 0.33 & 0.60 & 0.29 & 0.8 & 1.3 & 1.6 \\
2006 & 25 & 0.84 & 0.20 & 0.48 & 0.36 & 0.31 & 3.7 & 2.7 & 3.0 \\
2009 & 27 & 0.93 & 0.12 & 0.27 & 0.38 & 0.25 & 3.0 & 2.3 & 2.7 \\
$\begin{array}{c}\text { Agriculture } \\
2003\end{array}$ & 15 & 0.93 & 0.33 & 0.66 & 0.56 & 0.49 & 2.4 & 2.6 & 2.7 \\
2006 & 25 & 1.00 & 0.28 & 0.60 & 0.46 & 0.40 & 6.2 & 3.4 & 2.7 \\
2009 & 27 & 1.00 & 0.22 & 0.45 & 0.37 & 0.28 & 5.6 & 3.8 & 2.2 \\
Environment & & & & & & & & & \\
2003 & 15 & 0.93 & 0.20 & 0.36 & 0.35 & 0.26 & 1.4 & 2.1 & 1.8 \\
2006 & 25 & 0.98 & 0.17 & 0.44 & 0.44 & 0.33 & 3.3 & 2.6 & 2.3 \\
2009 & 27 & 0.96 & 0.15 & 0.44 & 0.43 & 0.37 & 3.7 & 2.2 & 2.5 \\
Taxation & & & & & & & & & \\
2003 & 15 & 0.73 & 0.22 & 0.32 & 0.38 & 0.33 & 2.7 & 2.9 & 3.1 \\
2006 & 25 & 0.88 & 0.18 & 0.33 & 0.45 & 0.32 & 3.6 & 3.1 & 3.3 \\
2009 & 27 & 0.74 & 0.15 & 0.41 & 0.40 & 0.27 & 2.9 & 2.5 & 2.5 \\
Justice & & & & & & & & & \\
2006 & 25 & 0.84 & 0.22 & 0.52 & 0.39 & 0.36 & 4.1 & 2.8 & 3.1 \\
2009 & 27 & 0.93 & 0.12 & 0.34 & 0.40 & 0.27 & 3.0 & 2.2 & 2.1 \\
Competition & & & & & & & & & \\
2006 & 25 & 0.84 & 0.21 & 0.38 & 0.45 & 0.30 & 3.9 & 3.1 & 2.8 \\
2009 & 27 & 0.78 & 0.15 & 0.36 & 0.40 & 0.31 & 3.1 & 2.5 & 2.6 \\
\hline \hline
\end{tabular}


Table 2: Member states' policy positions on the sugar sector reform

\begin{tabular}{|c|c|c|}
\hline Issue & Positions & Member states \\
\hline \multirow{7}{*}{ Size of price cut } & No cut (high subsidy) & PL \\
\hline & "Much smaller cut" than proposed & CY, EL, IT, ES \\
\hline & "Smaller cut" than proposed by the & \\
\hline & Commission & FI, HU, IE, LV, LT, PT, SI \\
\hline & Cut of $33 \%$ & AT, LU, NL \\
\hline & Cut of $39 \%$ & BE, CZ, FR, DE, MT, SK, UK \\
\hline & $\begin{array}{l}\text { Cut of more than } 39 \% \text { (low } \\
\text { subsidy) }\end{array}$ & DK, EE, SE \\
\hline \multirow{5}{*}{$\begin{array}{l}\text { Amount of } \\
\text { compensation for } \\
\text { sugar producers }\end{array}$} & $100 \%$ compensation & EL, HU, IT, LV, LT, PL, PT, ES \\
\hline & $\begin{array}{l}\text { "More compensation" than } \\
\text { proposed by the Commission }\end{array}$ & AT, BE, FI, IE, SI \\
\hline & $60 \%$ compensation & CZ, FR, DE, LU, NL, SK \\
\hline & $40 \%$ compensation & MT, SE, UK \\
\hline & Complete liberalization & DK \\
\hline \multirow{2}{*}{$\begin{array}{l}\text { Merging of } A \text { and } \\
B \text { quotas }\end{array}$} & Merge quotas then cut & $\begin{array}{l}\text { AT, BE, DK, FI, FR, DE, EL, IE, } \\
\text { IT, NL, PT, ES, SE, UK }\end{array}$ \\
\hline & $\begin{array}{l}\text { Cut B-quotas first, then A-quotas if } \\
\text { necessary }\end{array}$ & CZ, HU, LV, LT, PL, SI, SK \\
\hline
\end{tabular}


Table 3: SAOM analysis of Coreper I

\begin{tabular}{|c|c|c|c|c|}
\hline & (1) & (2) & (3) & (4) \\
\hline Constant rate (2003-06) & $\begin{array}{l}61.32 \\
(8.79)\end{array}$ & $\begin{array}{c}189.31 \\
(8.26)\end{array}$ & $\begin{array}{l}86.18 \\
(8.12)\end{array}$ & $\begin{array}{c}36.86 \\
(18.27)\end{array}$ \\
\hline Constant rate (2006-09) & $\begin{array}{c}6.70 \\
(0.99)\end{array}$ & $\begin{array}{c}6.86 \\
(0.98)\end{array}$ & $\begin{array}{c}7.43 \\
(1.12)\end{array}$ & $\begin{array}{c}7.52 \\
(1.05)\end{array}$ \\
\hline Outdegree (density) & $\begin{array}{c}-1.130^{* * *} \\
(0.069)\end{array}$ & $\begin{array}{c}-1.165^{* * *} \\
(0.079)\end{array}$ & $\begin{array}{c}-1.147^{* * *} \\
(0.117)\end{array}$ & $\begin{array}{c}-2.277^{* * *} \\
(0.345)\end{array}$ \\
\hline Reciprocity & $\begin{array}{l}0.714^{\text {*** }} \\
(0.149)\end{array}$ & $\begin{array}{c}0.658^{\text {*** }} \\
(0.168)\end{array}$ & $\begin{array}{c}0.452^{* *} \\
(0.203)\end{array}$ & $\begin{array}{c}0.534^{* *} \\
(0.238)\end{array}$ \\
\hline Preference similarity (all) & & $\begin{array}{l}0.845^{\text {*** }} \\
(0.277)\end{array}$ & $\begin{array}{l}0.729^{* * *} \\
(0.258)\end{array}$ & $\begin{array}{c}0.593^{*} \\
(0.338)\end{array}$ \\
\hline Transitive triad & & & $\begin{array}{c}0.160^{* *} \\
(0.068)\end{array}$ & $\begin{array}{c}0.057 \\
(0.154)\end{array}$ \\
\hline Facilitating triad & & & $\begin{array}{c}0.100^{* *} \\
(0.044)\end{array}$ & $\begin{array}{l}0.313^{\text {*** }} \\
(0.097)\end{array}$ \\
\hline Outdegree, activity & & & & $\begin{array}{l}0.056^{* * *} \\
(0.020)\end{array}$ \\
\hline Indegree, popularity & & & & $\begin{array}{l}0.241^{* * *} \\
(0.081)\end{array}$ \\
\hline
\end{tabular}

Note:

${ }^{*} p<0.1 ;{ }^{* *} p<0.05 ;{ }^{* * *} p<0.01$ 
Table 4: SAOM analysis of three-waved committees

\begin{tabular}{|c|c|c|c|c|c|c|c|c|}
\hline & \multicolumn{2}{|c|}{ Agriculture } & \multicolumn{2}{|c|}{ Environment } & \multicolumn{2}{|c|}{ Taxation } & \multicolumn{2}{|c|}{ Multilevel-macro $^{a}$} \\
\hline & $(5)$ & $(6)$ & $(7)$ & $(8)$ & (9) & $(10)$ & $(11)$ & $(12)$ \\
\hline Constant rate (2003-06) & $\begin{array}{r}187.63 \\
(7.57)\end{array}$ & $\begin{array}{l}60.26 \\
(9.87)\end{array}$ & $\begin{array}{l}15.79 \\
(3.63)\end{array}$ & $\begin{array}{l}17.99 \\
(5.30)\end{array}$ & $\begin{array}{l}57.83 \\
(8.25)\end{array}$ & $\begin{array}{c}34.27 \\
(23.68)\end{array}$ & & \\
\hline Constant rate (2006-09) & $\begin{array}{c}6.60 \\
(1.00)\end{array}$ & $\begin{array}{c}7.09 \\
(1.19)\end{array}$ & $\begin{array}{c}6.86 \\
(0.97)\end{array}$ & $\begin{array}{c}8.13 \\
(1.35)\end{array}$ & $\begin{array}{c}7.06 \\
(1.05)\end{array}$ & $\begin{array}{c}7.87 \\
(1.44)\end{array}$ & & \\
\hline Outdegree (density) & $\begin{array}{l}-1.295^{* * *} \\
(0.090)\end{array}$ & $\begin{array}{l}-2.914^{* * *} \\
(0.529)\end{array}$ & $\begin{array}{l}-1.137^{* * *} \\
(0.079)\end{array}$ & $\begin{array}{l}-1.662^{* * *} \\
(0.415)\end{array}$ & $\begin{array}{l}-1.183^{* * *} \\
(0.074)\end{array}$ & $\begin{array}{l}{ }^{*}-1.981^{* * *} \\
(0.337)\end{array}$ & $\begin{array}{l}*-1.172^{* * *} \\
(0.041)\end{array}$ & $\begin{array}{l}-2.652^{* * *} \\
(0.205)\end{array}$ \\
\hline Reciprocity & $\begin{array}{l}0.774^{* * *} \\
(0.202)\end{array}$ & $\begin{array}{l}0.643^{* * *} \\
(0.234)\end{array}$ & $\begin{array}{l}0.998^{* * *} \\
(0.161)\end{array}$ & $\begin{array}{r}0.373^{*} \\
(0.200)\end{array}$ & $\begin{array}{l}0.607^{* * *} \\
(0.167)\end{array}$ & $\begin{array}{c}0.317 \\
(0.223)\end{array}$ & $\begin{array}{l}0.795^{* * *} \\
(0.076)\end{array}$ & $\begin{array}{l}0.704^{* * *} \\
(0.109)\end{array}$ \\
\hline $\begin{array}{l}\text { Preference similarity } \\
\text { (by committee) }\end{array}$ & $\begin{array}{l}0.795^{* * *} \\
(0.216)\end{array}$ & $\begin{array}{l}0.662^{* *} \\
(0.307)\end{array}$ & $\begin{array}{l}1.037^{* * *} \\
(0.315)\end{array}$ & $\begin{array}{l}0.945^{* * *} \\
(0.343)\end{array}$ & $\begin{array}{l}0.938^{* * *} \\
(0.245)\end{array}$ & $\begin{array}{c}0.644^{* *} \\
(0.288)\end{array}$ & $\begin{array}{l}1.312^{* * *} \\
(0.147)\end{array}$ & $\begin{array}{l}0.969^{* * *} \\
(0.199)\end{array}$ \\
\hline Transitive triad & & $\begin{array}{c}0.037 \\
(0.143)\end{array}$ & & $\begin{array}{l}0.277^{* * *} \\
(0.098)\end{array}$ & & $\begin{array}{r}0.172^{*} \\
(0.101)\end{array}$ & & $\begin{array}{c}0.015 \\
(0.063)\end{array}$ \\
\hline Facilitating triad & & $\begin{array}{l}0.367^{* * *} \\
(0.117)\end{array}$ & & $\begin{array}{l}0.268^{* * *} \\
(0.092)\end{array}$ & & $\begin{array}{l}0.246^{* * *} \\
(0.088)\end{array}$ & & $\begin{array}{l}0.343^{* * *} \\
(0.054)\end{array}$ \\
\hline Outdegree, activity & & $\begin{array}{r}0.049^{*} \\
(0.027)\end{array}$ & & $\begin{array}{c}-0.004 \\
(0.028)\end{array}$ & & $\begin{array}{c}0.022 \\
(0.020)\end{array}$ & & $\begin{array}{l}0.047^{* * *} \\
(0.012)\end{array}$ \\
\hline Indegree, popularity & & $\begin{array}{l}0.323^{* * *} \\
(0.110)\end{array}$ & & $\begin{array}{c}0.141 \\
(0.089)\end{array}$ & & $\begin{array}{l}0.182^{* *} \\
(0.077)\end{array}$ & & $\begin{array}{l}0.304^{* * *} \\
(0.048)\end{array}$ \\
\hline
\end{tabular}

${ }^{a}$ For detailed information about constant rates, see the supporting information. 
Table 5: SAOM analysis of two-waved committees

\begin{tabular}{|c|c|c|c|c|}
\hline & \multicolumn{2}{|c|}{ Justice } & \multicolumn{2}{|c|}{ Competition } \\
\hline & (13) & (14) & (15) & (16) \\
\hline Constant rate (2006-09) & $\begin{array}{c}7.87 \\
(1.06)\end{array}$ & $\begin{array}{c}8.05 \\
(1.44)\end{array}$ & $\begin{array}{c}7.70 \\
(1.03)\end{array}$ & $\begin{array}{c}7.97 \\
(1.27)\end{array}$ \\
\hline Outdegree (density) & $\begin{array}{c}-1.433^{* * *} \\
(0.120)\end{array}$ & $\begin{array}{l}-3.523^{* * *} \\
(1.235)\end{array}$ & $\begin{array}{l}-1.414^{* * *} \\
(0.124)\end{array}$ & $\begin{array}{c}-3.872^{* * *} \\
(1.163)\end{array}$ \\
\hline Reciprocity & $\begin{array}{l}0.716^{* * *} \\
(0.235)\end{array}$ & $\begin{array}{c}0.229 \\
(0.328)\end{array}$ & $\begin{array}{l}0.756^{* * *} \\
(0.245)\end{array}$ & $\begin{array}{c}0.340 \\
(0.334)\end{array}$ \\
\hline $\begin{array}{l}\text { Preference similarity } \\
\text { (by committee) }\end{array}$ & $\begin{array}{l}1.129^{*} \\
(0.599)\end{array}$ & $\begin{array}{c}0.849 \\
(0.725)\end{array}$ & $\begin{array}{c}0.724^{*} \\
(0.417)\end{array}$ & $\begin{array}{c}0.640 \\
(0.538)\end{array}$ \\
\hline Transitive triad & & $\begin{array}{c}0.220 \\
(0.156)\end{array}$ & & $\begin{array}{c}0.195 \\
(0.162)\end{array}$ \\
\hline Facilitating triad & & $\begin{array}{l}0.443^{* *} \\
(0.202)\end{array}$ & & $\begin{array}{l}0.467^{* * *} \\
(0.174)\end{array}$ \\
\hline Outdegree, activity & & $\begin{array}{c}-0.007 \\
(0.046)\end{array}$ & & $\begin{array}{c}0.009 \\
(0.054)\end{array}$ \\
\hline Indegree, popularity & & $\begin{array}{r}0.443^{*} \\
(0.202)\end{array}$ & & $\begin{array}{l}0.359^{* *} \\
(0.162)\end{array}$ \\
\hline
\end{tabular}




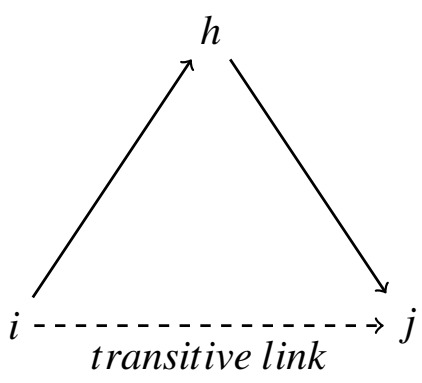

(a) A transitive triad

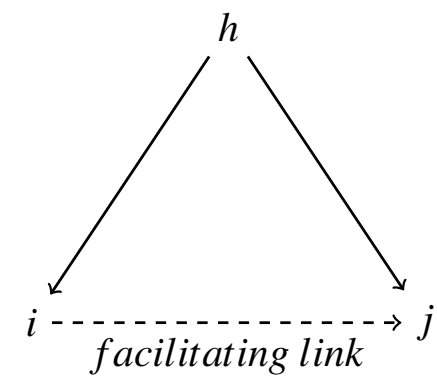

(b) A facilitating triad

Figure 1: Facilitating and transitive links between member states $i$ and $j$ 


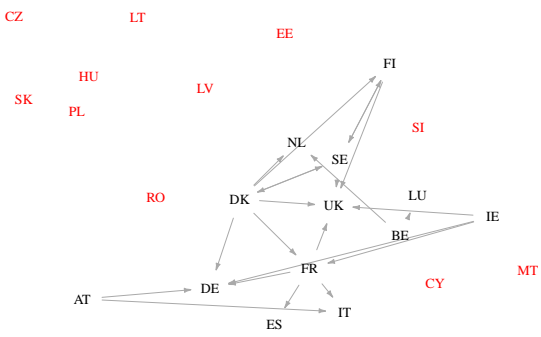

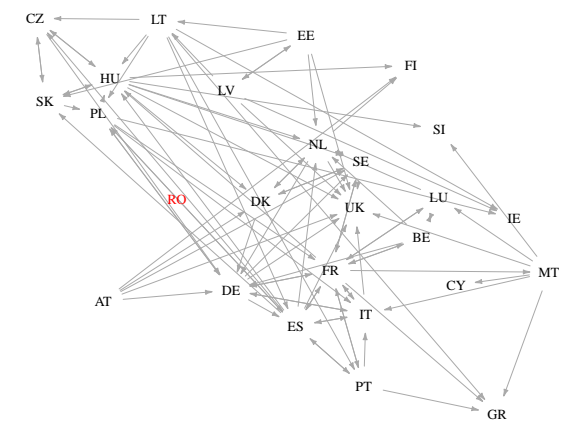

(b) 2006

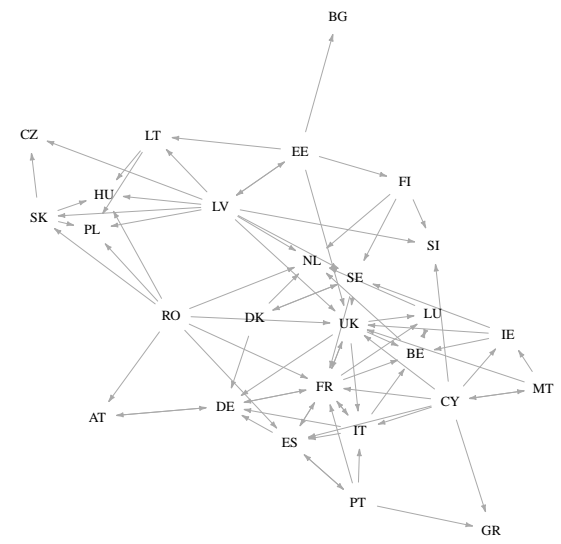

(c) 2009

Figure 2: Cooperative networks in Corper I Note: States of red colors are non-EU members when the surveys were conducted. 


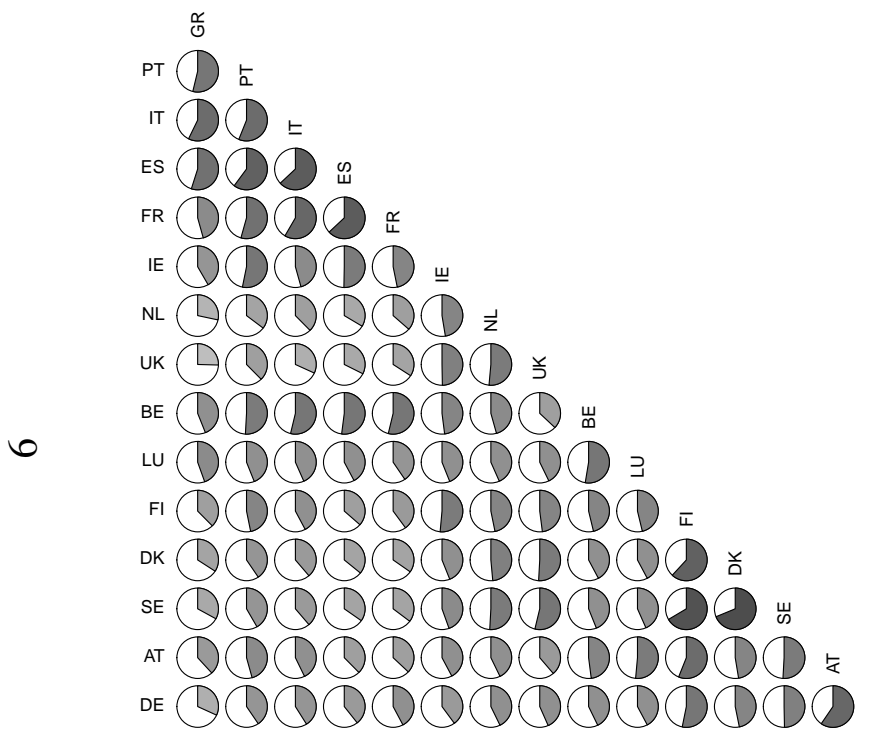

(a) 2003

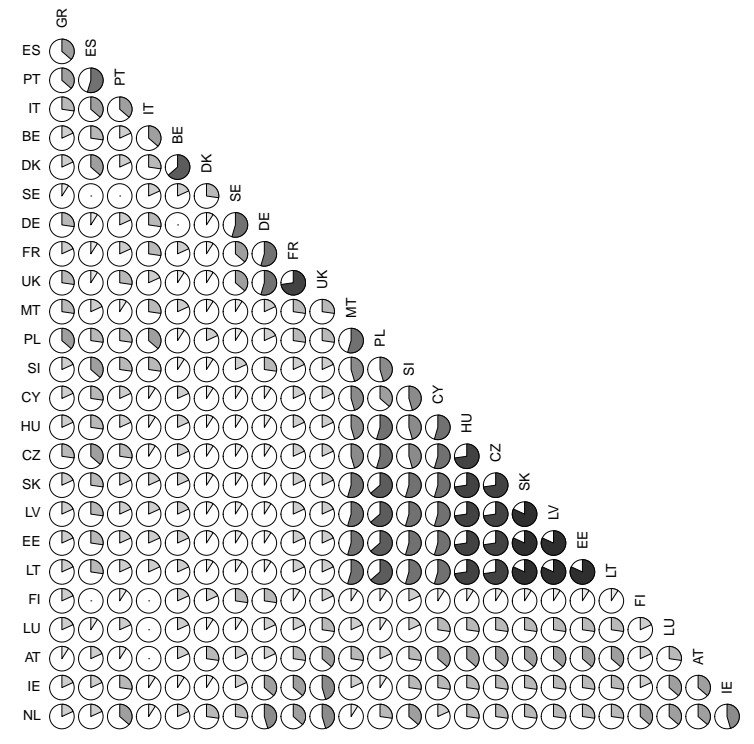

(b) 2006

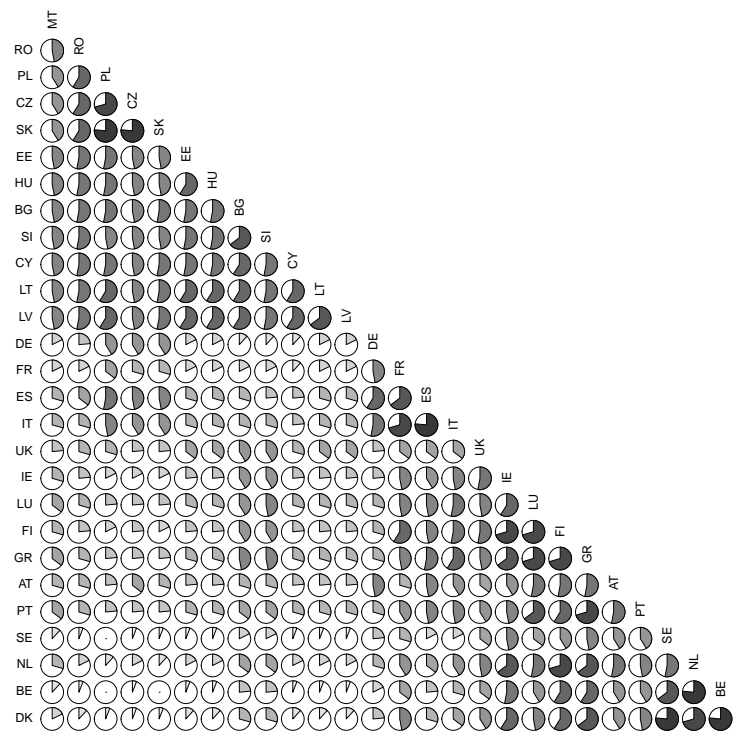

(c) 2009

Figure 3: Dyadic preference similarity in Coreper I (all proposals included) Note: States are ordered based on results of hierarchical clustering of similarity scores. 


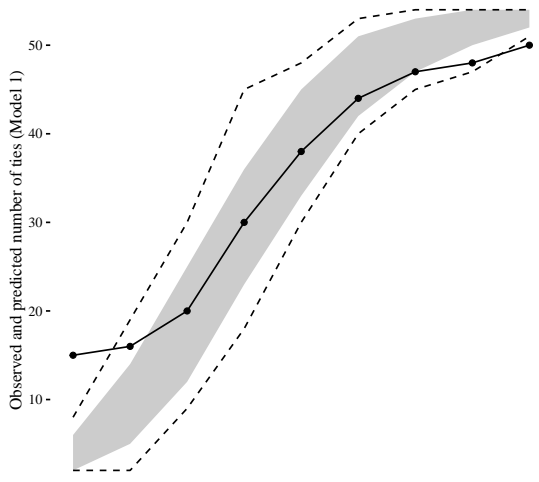

$\begin{array}{cccc}0- & \dot{1} & \dot{4} & \dot{6} \\ 0 & \text { Outdegree (Proposed cooperative ties) }\end{array}$

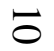

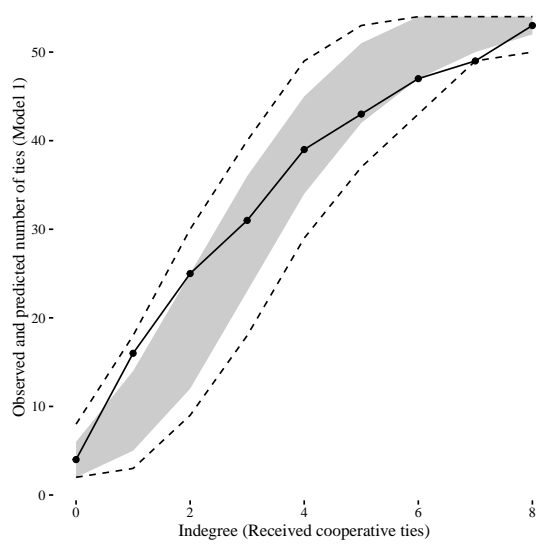

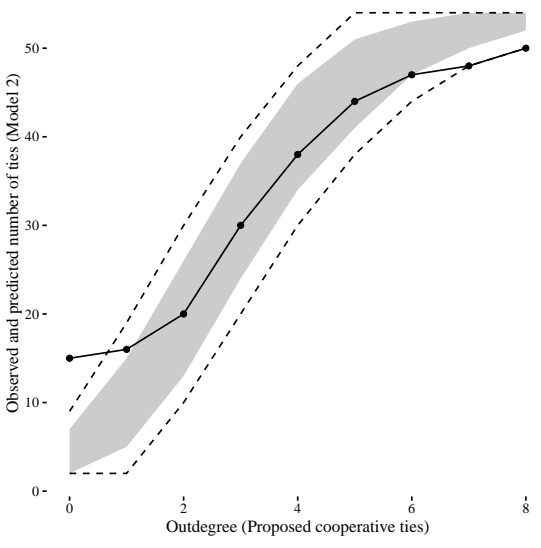
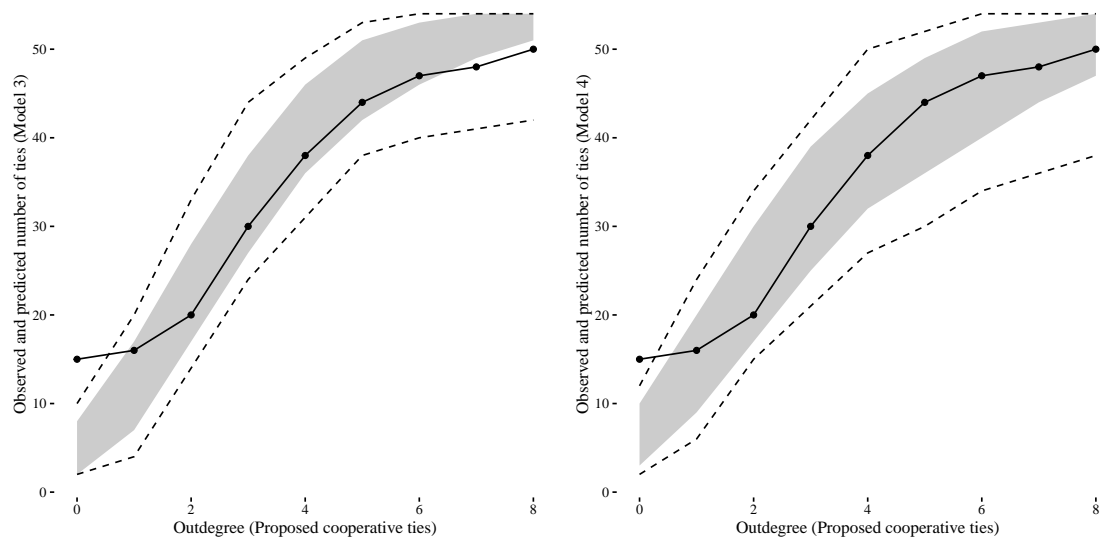

(a) Outdegree (Proposed cooperative ties)
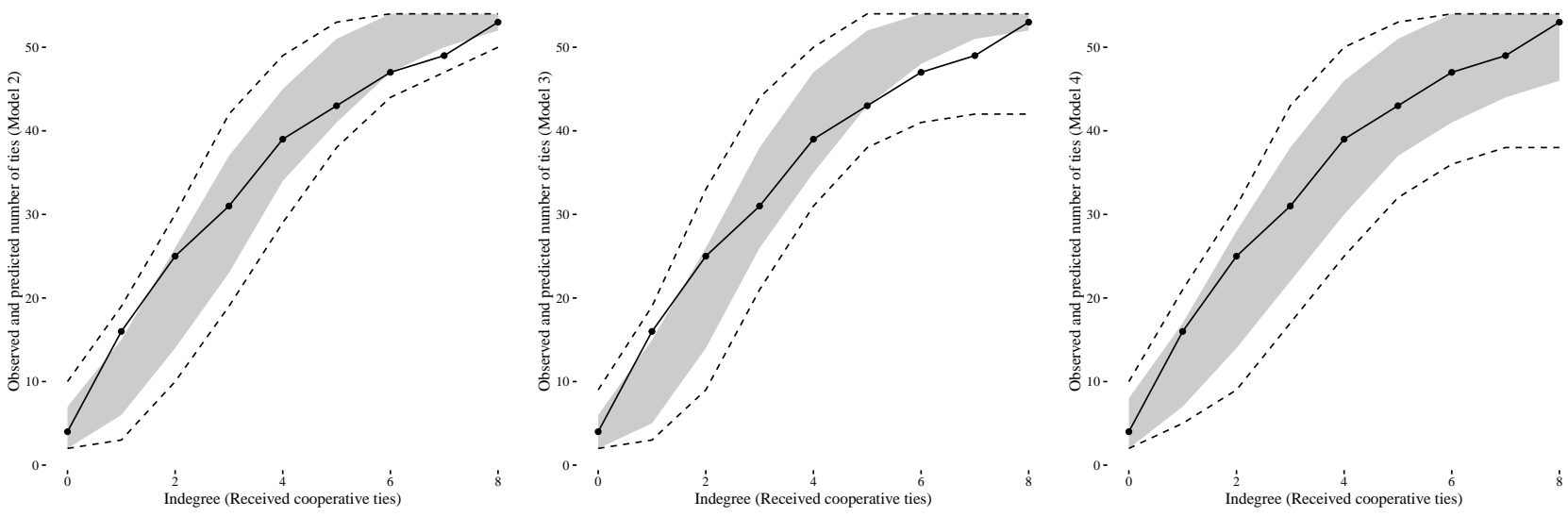

(b) Indegree (Received cooperative ties)

Figure 4: Goodness of Fit of the Coreper I SAOM models in Table 1 

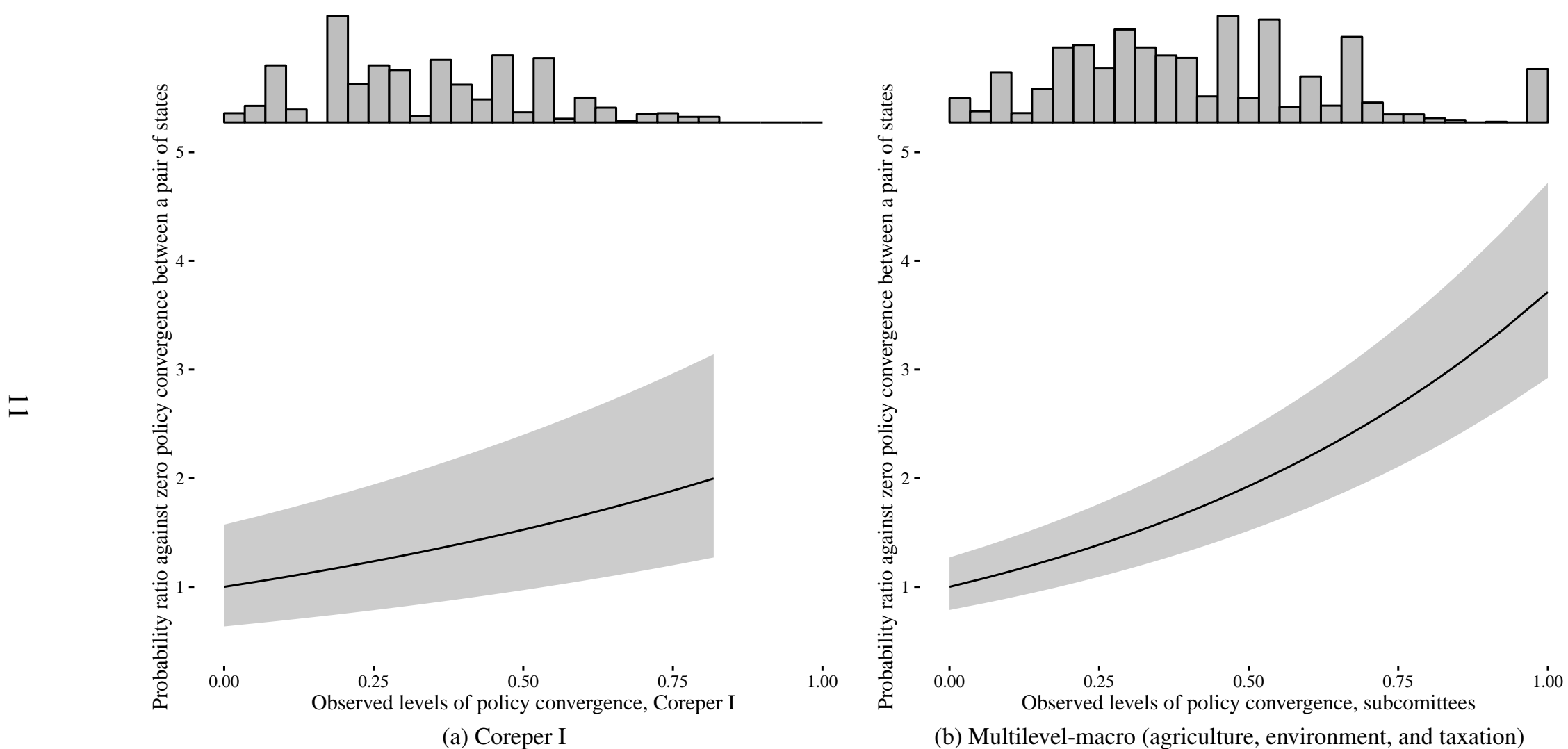

(b) Multilevel-macro (agriculture, environment, and taxation)

Figure 5: Expected impacts of policy congruence on cooperation initiation 